\title{
The Moral Status of the Reclamation of Slurs
}

\author{
Bianca Cepollaro*
}

Received: 18 December 2020 / Accepted: 4 June 2021

Abstract: While prototypical uses of slurs express contempt for targets, some reclaimed uses are associated with positive evaluations. This practice may raise concerns. I anticipate this criticism in what I dub the Warrant Argument (WA) and then defend the legitimacy of this kind of reclamation. For the WA, standard pejorative uses of slurs are problematic for assuming unwarranted connections between descriptive properties (e.g., being gay) and value judgements (e.g., being worthy of contempt). When reclaimed uses of slurs express a positive evaluation of their targets - the WA goes-reclamation fails to challenge the unwarranted link between descriptive properties and value judgements, and merely reverses the evaluation polarity from negative to positive. So, the WA concludes, reclaimed uses of slurs evaluating targets positively for belonging to a certain group make a similar moral error as derogatory uses of slurs (sections 2-3). The WA could lead us to condemn reclamation. To resist this conclusion, I draw a parallel with affirmative action, arguing that it can be morally permissible to balance an existing form of injustice by temporarily introducing a countervailing mechanism that prima facie seems to violate the norm of equality: even if the WA were right, it wouldn't constitute an argument against the moral permissibility of reclamation in the case of most slurs (section 4). This line of

* Vita-Salute San Raffaele University

(D) https://orcid.org/0000-0003-2695-2125

- Università Vita-Salute San Raffaele Via Olgettina, 58, 20132 Milano, Italy.

$\triangle$ cepollaro.biancamaria@unisr.it

(C) The Author. Journal compilation (C) The Editorial Board, Organon F.

This article is distributed under the terms of the Creative Commons Attribution-NonCommercial 4.0 International Public License (CC BY-NC 4.0). 
argument in defense of pride reclamation may also serve to debunk the myths of reverse racism and reverse sexism (section 5).

Keywords: Hate speech; polarity reversal; reclamation; reverse racism; reverse sexism; slurs.

\section{Introduction}

While prototypical uses of slurs often express contempt for targets, some reclaimed uses of such epithets are associated with a positive evaluation of the target class. This practice - let's call it 'pride reclamation'-may raise concerns under certain readings. In this paper, I anticipate this criticismsummarized in what I dub the Warrant Argument (WA) - and defend the legitimacy of this kind of reclamation. According to the WA, what is problematic with standard pejorative uses of slurs is that they assume an unwarranted connection between descriptive properties (such as being gay, being Italian, being Jewish and so on) and value judgements (being bad, being worthy of contempt and the like). When reclaimed uses of slurs express pride and/or a positive evaluation of their targets - the WA goesthey fail to challenge such a wrong link between descriptive properties and value judgements, and merely manage to reverse the polarity of the value judgement from negative to positive, from contempt to pride. So, the WA concludes, reclaimed uses of slurs expressing a positive evaluation of the slur's targets make a similar moral error as ordinary derogatory uses of slurs (sections 2-3). The WA could lead us to condemn or even ban pride reclamation, just like we do with derogatory uses of slurs. To resist this conclusion, I draw a parallel with the mechanisms of affirmative action, to argue that it can be morally permissible to balance an existing form of injustice by temporarily introducing a countervailing mechanism that prima facie seems a violation of the norm of equality: the analogy with affirmative action suggests that, even if the WA were right, it wouldn't constitute an argument against the moral permissibility of pride reclamation in the case of most slurs (section 4). Finally, I show how this line of argument in defense of pride reclamation may also serve to debunk the myths of reverse racism and reverse sexism (section 5). 


\section{The moral mistake of slurring}

Slurring is to derogate people on the basis of their belonging to a certain category that typically has to do with race, sexual orientation, gender, nationality, religion and so on (see i.e. Saka 2007; Hom 2008; Richard 2008). What distinguishes slurs from other pejoratives such as 'asshole' or 'jerk' is that only the former target people qua members of a social group. A slur like 'wop' does not merely derogate an Italian person, but attacks her because she is Italian.

Scholars have developed different theories as to how to analyze slurs and their pejorative content (see Hess forthcoming for a rich but concise survey). In this paper, I stay neutral with respect to two central aspects: (i) how slurs convey the derogatory content with which they are associated (i.e., whether the derogatory content is lexically encoded or not; and if it is, how), and (ii) how such a derogatory content should be spelt out. With respect to these issues, I will just adopt two general assumptions that are compatible with most existing accounts of slurs: (i) standard uses of epithets are systematically associated with derogatory contents and (ii) the derogatory content of slurs - however it is conveyed - amounts to something roughly like 'bad for being $\mathrm{P}$ ', where ' $\mathrm{P}$ ' is a descriptive property such as being gay, being Black, being Italian, etc. Let me briefly elaborate on both points.

Regarding (i), the use of slurs conveys pejorative contents across contexts, regardless of the intentions of the speaker; moreover, it conveys such contents even when slurs are embedded under semantic operators. In fact, the derogatory content of epithets displays a striking feature that has attracted a good deal of attention from linguists and philosophers of language in the past years, namely projection (see i.a. Potts 2005; Schlenker 2007; Anderson and Lepore 2013; Jeshion 2013a, 2013b; Bolinger 2015; Nunberg 2018; Camp 2018). 'Projection' refers to the fact that the derogatory content of slurs survives in the interaction with many semantic operators, i.e., projects out of semantic embedding. Take the sentence 'Lucia is a wop'. The derogatory content towards Italian people - however we prefer to spell it out - survives when we embed the sentence under negation, in the antecedent of a conditional, in a question or a modal: 'Lucia is not a wop', 'If Lucia is a wop, her brother is too', 'Is Lucia a wop?', 'Lucia might be a 
wop'. As one can see, the derogatory content of slurs is very hard to suspend, at least in their non-reclaimed uses.

As for (ii), it suggests that what slurs do in general is to express a negative evaluation (often characterized as contempt) based on some descriptive properties (e.g., being gay, being Black, being Italian, etc.) that do not warrant per se a negative evaluation. Using slurs thus involves a morally wrong connection between a descriptive property and a value judgement. Such a link between the descriptive property and the evaluation is not merely correlational: from the perspective that the use of slurs encourages, targets do not just happen to be bad; they are bad because they satisfy a certain descriptive property (e.g., being Italian, gay, Black and so on). Suppose that research finds out that every single Italian person is bad in some respects: if you know that someone is Italian, you automatically know that $\mathrm{s} /$ he is bad in some way. This correlational claim that every Italian is bad in some respect would still differ from the racist assumption conveyed by uses of 'wop' that an Italian is bad for being Italian. In this paper I assume that the idea that being from a certain country (as well as having a certain sexual orientation, gender, religion, etc.) makes an individual worthy of a negative evaluation is morally wrong.

The morally problematic assumption that the use of slurs expresses and promotes, together with the endurance and pervasiveness of their derogatory content, makes epithets particularly toxic and dangerous. It is not surprising that slurs are typically banned from the public debate in liberal democracies (see i.a. Stanley 2015) and some scholars advocated silentist positions, according to which any occurrence of slurs - including mere mention - is offensive and should be therefore banned (Anderson and Lepore 2013). There are non-derogatory occurrences of slurs, though, that usually survive most kinds of censorship: they are the so-called reclaimed uses of epithets, to which we now turn.

\section{Pride reclamation of slurs and the Warrant Argument criticism}

Reclamation is the phenomenon for which speakers, typically members of the target group, can use a slur in such a way that the pejorative is not 
offensive anymore in those contexts; in contrast, reclaimed slurs often convey positive contents and attitudes about the target class, they typically express pride, intimacy, solidarity, and camaraderie (see Tirrell, 1999; Brontsema, 2004; Croom 2011, 2013, 2014; Bianchi 2014; Miščević and Perhat 2016; Ritchie 2017; Anderson 2018; cf. Burnett 2020 and Zeman 2021).

Even though it is unclear that all instances of reclamation do so, at least some reclaimed uses of derogatory epithets seem to switch the standard evaluative content of slurs from negative into positive, thus turning contempt into pride (i.a., Kennedy 2002; Ritchie 2017; Jeshion 2020, PopaWyatt 2020). Under a very general characterization, these reclaimed uses of slurs convey something along the line of 'good for being P' (Ritchie 2017). I dub these uses 'pride reclamation'.

Many scholars got interested in reclamation because it constitutes an instance of meaning change (a temporary or stable change, according to different views) that challenges most existing accounts of slurs. Others, like Bianchi (2014), underline further interesting aspects: reclamation has proved so far one of the most effective tools to get rid of the toxic and harmful powers of slurs. For Bianchi (2014), while reclamation weakens the toxicity of slurs, silentism risks to worsen it: this is why reclamation should be encouraged and reclaimed uses of slurs should not be banned nor censored. In this picture, reclamation is presented as a possible way to counteract racism, homophobia and discrimination, and scholars have pointed out the benefits of reclamation with respect to empowerment (see i.a. Croom 2014). This view is also supported by empirical studies (see for instance Galinsky et al. 2003; Galinsky et al. 2013), according to which selflabeling - applying a slur to oneself-has important empowering effects.

Not everyone agrees, however: scholars such as Bailey et al. (1998) have illustrated a wide range of attitudes vis-à-vis the practice of reclamation, from very positive to very negative. The detractors of reclamation have various strings to their bow: they can argue that reclamation is self-defeating because it ultimately disguises self-contempt (Kennedy 2002). They may worry that it ends up legitimizing the use of slurs in a dangerous way (Herbert 2015), for instance by suggesting that certain terms are harmless and can be used inconsiderately. It could be maintained that reclamation 
contributes to the linguistic segregation of targets, thus worsening their overall social segregation, and so on.

In this paper, I anticipate and reject a different worry, summarized in what I call the Warrant Argument (WA). According to the WA, instances of reclamation conveying a positive evaluation of the target class ('good for being $\mathrm{P}^{\prime}$ ) are morally problematic in that they end up making a similar moral mistake to the one standard pejorative uses of slurs make. Recall what we have observed in section 2, namely that slurs express negative judgements of a subject on the basis of a descriptive property that does not warrant a negative evaluation per se. Those who find this morally problematic might also agree that being from a certain country (as well as having a certain sexual orientation, gender, religion, etc.) does not by itself make anyone good, just as much as it doesn't make one bad. If one acknowledges that being Italian (or gay or Black, etc.) does not warrant a negative value judgement - the WA goes - they should also acknowledge that it does not warrant a positive evaluation either. The WA does not assume that because a descriptive property $\mathrm{P}$ does not warrant a negative evaluation, then it cannot warrant a positive one at the same time - this would be trivially false. Rather, it takes it that the particular descriptive properties picked out by prototypical slurs (in relation to race, sexual orientation, gender, etc.) do not warrant per se any value judgement at all (neither positive nor negative). Since, as we saw, standard uses of slurs convey a negative evaluation and the reclaimed uses (at least some of them) convey a positive evaluation, the Warrant Argument — applied to 'wop' - goes as follows:

1. Standard uses of a slur like 'wop' convey the idea that being Italian in itself warrants a negative evaluation, and this is wrong, because being Italian never justifies any value judgement: there is nothing bad or good per se in being Italian.

2. Certain reclaimed uses of 'wop' convey the idea that being Italian is per se good, thus that it warrants a positive evaluation. This is wrong, because being Italian never justifies any value judgement: there is nothing bad or good in itself in being Italian.

3. So, certain reclaimed uses of 'wop' that convey a positive evaluation of Italians qua Italians make a similar moral mistake to the one made by standard negative uses of slurs. 
The WA leads one to conclude that both derogatory and reclaimed slurs encapsulate a moral mistake. This in turn may prompt the conclusion that also reclaimed slurs should be banned. Indeed, most existing accounts of reclamation suggest that what reclamation does to slurs (especially at its early stages) is to reverse the polarity of the evaluation (or expressive content, depending on the account one favors) from negative to positive. On these accounts, reclamation (at least at its earlier stages) does not challenge the unwarranted link-associated with slurring - between a property such as being Italian, being Black, being gay, etc. and a value judgement.

One could stop the WA right here by suggesting that there is an important difference between pride and contempt, between expressing positive and negative evaluations. One could say that the WA shouldn't lead to conclude that reclamation has to be banned simply because while violence and harm follow from hate speech, nothing similar is likely to follow from reclamation. In fact, pride per se doesn't need to involve a feeling of superiority over everyone else (cf. recognition vs. appraisal respect in Darwall 1977). This strategy to stop the WA is more problematic that it seems, because it's not so clear that positively connoted social terms are harmless: think, for instance, of how 'Aryan' was used by Nazis. Think what it would be like if slurs against white people were reclaimed (?). Invoking a deep asymmetry between social terms associated with positive rather than negative contents may not be enough to stop the WA from banning reclamation. In this paper, I signal a longer route to do so. The advantage of this longer journey is that by granting more to the WA, its conclusion in favor of the moral permissibility of reclamation should be appealing to a larger audience. Finding answers to the WA that can be shared widely is especially important, given the connection with the myth of reverse racism or sexism to which I'll turn in section 5 .

This said, if we accept, with the WA, that certain kinds of reclamation encapsulate and endorse a faulty connection between descriptive properties regarding social groups and unwarranted evaluations, could such a practice of reclamation be nevertheless morally permissible? In the next session I present a parallel with affirmative action, aimed at maintaining that reclamation is morally permissible, notwithstanding the criticism from the Warrant Argument. 
Before moving to the next section, let me remark that not all accounts of reclamation need to deal with the WA, as not all approaches grant that reclaimed uses of slurs involve 'polarity reversal', as Jeshion (2020) calls it. While many proposals (e.g., Ritchie 2017, Jeshion 2020, Popa-Wyatt 2020) do suggest that (at least some) reclaimed uses of slurs involve the expression of some positive content, other proposals don't need to. Take for instance Bianchi (2014), according to whom using a slur in a reclaimed way is (i) to evoke the standard derogatory content that slurs typically convey while (ii) expressing at the same time one's dissociative attitude towards it. In this framework, speakers need not express a positive attitude towards the target class; all they need is to dissociate from the negative attitudes associated with derogatory uses. Put differently, some accounts need not worry about whether the moral permissibility of certain kinds of reclamation is challenged by the WA, because their proposals do not subscribe to the second premise of the WA to begin with (i.e., the idea that at least some reclaimed uses of slurs convey a positive evaluation of the target class).

What about all the other theories according to which reclamation consists in polarity reversal? In the next section, I propose a way to respond to the challenge raised by the WA which is available to possibly any account of reclamation that subscribes to the second premise of the WA.

\section{In defense of pride reclamation: a parallel with affirmative action}

In this section I show that, despite appearances, the WA does not necessarily constitute an argument against the moral permissibility of reclamation, if we accept that it can be morally permissible to balance an existing form of injustice by temporarily introducing a countervailing mechanism that - taken out of context - may look like a violation of the norm of equality. To this end, I propose a parallel with a very different phenomenon in a very different domain: the debate on affirmative action. My proposal is to resist the conclusion that it is morally problematic for certain reclaimed uses of slurs to convey unwarranted positive evaluation of the target class, by understanding such uses of epithets as remedies meant to countervail 
existing power imbalances. To illustrate this parallel, let us look at affirmative action, typically defined along these lines:

Affirmative action means positive steps taken to increase the representation of women and minorities in areas of employment, education, and culture from which they have been historically excluded. When those steps involve preferential selection - selection on the basis of race, gender, or ethnicity - affirmative action generates intense controversy. (Fullinwider 2013)

Affirmative action gave rise to a lively debate concerning how to interpret it and, above all, how to engage in it, if at all (for a survey on the debate starting from the Seventies, see Fullinwider 2017). A possible way to understand affirmative action is the following: in order to balance an unjust mechanism (negative discrimination), it is morally admissible to introduce a countervailing kind of imbalance (positive discrimination) that is supposed to counteract the initial one over time. Consider the case of an unfair society characterized by systematic gender imbalances where women face undeserved barriers to employment. The employment practice in such a society discriminates on the basis of gender (negative discrimination). One measure that can help to fix this unfair situation is to resort to affirmative action and, in particular, to gender quotas that increase the employment rates of women and try to balance their exclusion (positive discrimination). Such a procedure is meant not only to (partially) balance the past exclusion, but also to start a virtuous circle where a gender-balanced work environment is more likely to avoid the exclusion of women in the future. In a sense (and this point attracted much criticism since the Seventies), affirmative action does not challenge the problem at its roots - i.e., it does not challenge discrimination as a matter of principle, nor does it call into question the fact that gender should not be crucial to whether one gets a job or not. It assumes that the best way to eradicate gender imbalances in the job market-rather than disavowing the very practice of taking the gender of the job candidate into account - is to temporarily modify the valence of discrimination (from negative to positive), in order to achieve anti-discriminatory results in the long run. One could thus say that affirmative action temporarily reproduces the problematic mechanisms it aims to fight, with an opposite valence: if a woman gets hired because of gender quotas (i.e., 
because she's a woman), one could say that the system keeps engaging in employment practices that "discriminate" on the basis of gender. Interestingly, most of the arguments employed to defend affirmative action and quotas are instrumental: they justify the introduction of certain mechanisms that prima facie violate the rule of equality in order to fix a previous widespread and systematic injustice. In the words of Goldman: "Thus short-run violations of the rule [of equality] are justified to create a more just distribution of benefits by applying the rule itself in future years" (Goldman 1979: 164-165). Affirmative action is morally justified in as much as it delivers positive results in balancing past discrimination and preventing ongoing and future discrimination. Indeed, a crucial point in the debate around affirmative action concerns the results it produces (for instance, concerning the effects of gender quotas, see Matland 2006; Franceschet and Piscopo 2008; Schwindt-Bayer 2009; Alexander 2012; Kittilson and Schwindt-Bayer 2012; Barnes and Burchard 2013; O'Brien and Rickne 2016).

Let's now go back to the reclamation of slurs. The parallel with affirmative action is meant to suggest that even though certain uses of reclaimed slurs convey the idea that merely belonging to a category makes a person worthy of positive evaluation, such uses are morally permissible in as much as they deliver beneficial results in taking the derogatory content off these terms in the long run. Even if one goes as far as to consider certain kinds of reclamation as short-run violations of the rule of equality (and they may look as such in accounts like Ritchie's), they would be interim solutions to fight the kind of prejudice and discrimination that slurs both express and spread. The question whether reclamation works as a measure to achieve such goals (empowering the victims of discrimination and turning the slur into a less powerful weapon in the long run) is to be investigated on empirical grounds. Experimental studies support the claim that reclamation delivers good results in terms of decreasing the perceived offensiveness of slurring terms and raising the subject's sense of empowerment. According to Galinsky et al. (2003) and Galinsky et al. (2013), the fact that people selfapply slurs has, on the one hand, important effects both on how powerful they feel and how powerful the observers perceive them; on the other hand, the self-application of the slur diminishes the perceived offensiveness of the 
term. Moreover, reclamation seems to have eventually succeeded in affecting the derogatory content in some cases: after a process of reclamation, 'queer' has today a new non-derogatory use that we can observe in expressions such as 'Queer Tango', 'Queer Film Festival', 'Queer Culture', 'Queer Studies', etc. (see Brontsema 2004). What is interesting is that the reclamation of 'queer' did not finally turn it into something like a positive sluri.e., a term conveying a positive value judgement on the target class qua category; rather, it simply made the term non-derogatory. The same might happen for many other reclaimed slurs.

I don't mean to put too much weight on the empirical claim that reclamation is beneficial; rather, I argue that if it is beneficial as it seems, then accepting the WA does not automatically mean banning reclamation, because - as the case of affirmative action shows - it can be morally permissible to balance an existing form of injustice by temporarily introducing a countervailing mechanism that may prima facie seem in violation of the norm of equality, if this measure proves beneficial on empirical grounds. So, if reclamation succeeds in securing beneficial empirical results, then it's safe from the censorship that could follow from the WA.

\section{A digression: Black Lives Matter and the myth of reverse racism}

The observations made so far may have further interesting applications beyond the debate on slurs, as this little digression will suggest. On June 6, 2017, the Black commentator and producer Lisa Durden appeared on Fox News' Tucker Carlson Tonight to discuss the issue of why it was legitimate for Black Lives Matter (BLM) to create a 'Black only' safe space for the Memorial Day Celebration. Tucker Carlson, a white conservative commentator, accused BLM of being racist: the whole point of BLM is to fight racism and nevertheless they were excluding people on the basis of race. Lisa Durden remarked “you've been having 'white day' forever, you don't say the words anymore 'cause you know it's politically incorrect, but you've had an all-white Oscars, all these movies with all-white actors, movie after movie after movie, (...) and over and over again". Carlson asked, "I just 
have a very simple question for you: if you don't like people excluding others on the basis of their race (...), why are you doing it?". Then again "If you don't like it, why are you perpetuating it?", "Do you think it's racist to exclude people on the basis of their skin color?". Durden answered, "I think it's racist when you've been excluding people for hundreds and hundreds of years and we are forced to come together collectively to celebrate ourselves because you guys won't; you are the largest society: let's be real here". After another exchange, Durden claimed, "Unfortunately, when you have a racist society like America, you force people to come together collectively to make sure that they have a voice". Durden was suspended and then fired from her position of adjunct professor at Essex County College in Newark.

I suggest that the issue discussed in this brief dialogue - was BLM being racist or not? - may be analyzed along the lines illustrated in the previous sections. It may be true that, strictly speaking, excluding people from an event on the basis of their race is something that in an ideal society shouldn't happen, as it would violate the norm of equality; however, in a racist society like the North-American one, it can be morally permissible to temporarily introduce a measure that prima facie violates the norm of equality that aims to balance a systemic form of injustice over time.

Similar observations apply more generally to the myth of reverse racism or sexism, according to which members of privileged groups (white people, men, etc.) are victims of the discrimination allegedly perpetuated by underprivileged groups (Black people, women). This kind of attitude suggests that the pursuit of an antiracist and antisexist society may result in the members of the privileged groups ending up being the victim of discrimination. One way to debunk this myth is by underlining how the rich and heterogeneous family of empowering measures (from celebrations in safe spaces to positive uses of slurs) are local and interim solutions to fight power imbalance in the face of systematic and ingrained forms of injustice. There may be a day when Black Lives Matter will not have reasons to exist, nor gender quotas. However, such a day has yet to come and, to say it with a slogan: to make things right, it may be not enough to just do things right. 


\section{Conclusion}

In this paper I argued that the moral permissibility of pride reclamation is not automatically ruled out by the WA: as other domains - like political representation and employment practices - show, it can be morally permissible to balance an existing form of negative discrimination by temporarily introducing a countervailing mechanism that seems prima facie to violate a norm of equality. This is not to suggest that reclamation and affirmative action are the same thing, but the disanalogies between the two do not seem to threaten my point. An interesting disanalogy worth mentioning is that while reclamation is typically determined and pursued by the group that is discriminated against (and, in some cases, their allies), affirmative action, in contrast, is usually decided from above and it is not mainly pursued or implemented by the discriminated group. Some could thus say that affirmative action involves a bit of paternalism that reclamation lacks. I shall leave the task of defending affirmative action from the charge of paternalism to another occasion, as I do not need the parallel between reclamation and affirmative action to go too far. But it is nevertheless interesting to note that, if one thinks that affirmative action could have nonbeneficial effects on the discriminated groups due to its character of a decision from above, this difficulty does not arise for reclamation, that is typically ignited and mainly carried out by the target class and its allies.

To conclude, in this paper I have anticipated and rejected a worry against the moral permissibility of pride reclamation, i.e., reclamatory uses of slurs conveying a positive evaluation of the target. I summarized this criticism in what I dubbed the Warrant Argument. According to the WA, standard and reclaimed uses of slurs make a similar moral error in that both assume an unwarranted connection between descriptive properties (such as being gay, being Italian, being Jewish and so on) and value judgements (being bad/good, being worthy of contempt/pride). The WA could lead us to condemn or ban pride reclamation, just like we do with derogatory uses of slurs, but I have proposed a parallel with the mechanisms of affirmative action that provides a way to resist this conclusion. The case of affirmative action shows that it can be morally permissible to balance an existing form of injustice by temporarily introducing a countervailing mechanism that 
prima facie seems to violate the norm of equality, if the measure proves effective in fighting oppression. The analogy with affirmative action suggests that, even if the WA were right, it wouldn't constitute an argument against the moral permissibility of pride reclamation. This strategy to defend the moral permissibility of reclamation from the WA is not the most direct one, as one could simply reject one of WA's premises. The advantage of this longer journey is that by granting more to the WA, its conclusion should be appealing to a larger audience.

\section{Acknowledgements}

Many thanks to Dan Zeman for putting together such a rich special issue and a wonderful workshop, Value in language (March 29-31, 2021, Slovak Academy of Sciences). Thanks to all the participants for their insights. In particular, I shall thank for their suggestions Victor Carranza, Nils Franzén, Leopold Hess, Robin Jeshion, Zuzanna Jusińsk, Stefano Predelli, Andrés Soria Ruiz, Pekka Väyrynen, Julia Zakkou and Dan Zeman. I have also benefitted from the insights of Claudia Bianchi, Laura Caponetto, Teresa Marques and Dan Zeman, commenting on earlier versions of this work.

\section{References}

Alexander, Amy C. 2012. "Change in Women's Descriptive Representation and the Belief in Women's Ability to Govern: A Virtuous Cycle." Politics 83 Gender 8 (4): 437-64. https://doi.org/10.1017/S1743923X12000487

Allan, Keith. 2015. "When Is a Slur not a Slur? The Use of nigger in 'Pulp Fiction'”. Language Sciences 52: 187-99. https://doi.org/10.1016/j.langsci.2015.03.001

Anderson, Luvell. 2018. "Calling, Addressing, and Appropriation." In Bad Words: Philosophical Perspectives on Slurs, edited by David Sosa, 15-37. Oxford, Oxford University Press. 10.1093/oso/9780198758655.003.0002

Anderson, Luvell, and Ernie Lepore. 2013. "Slurring Words." Noûs 47 (1): 25-48. https://doi.org/10.1111/j.1468-0068.2010.00820.x

Asim, Jabari. 2007. The $N$ Word: Who Can Say It, Who Shouldn't, and Why. New York-Boston: Houghton Mifflin Company.

Bailey, Guy, John Baugh, Salikoko S. Mufwene, and John R. Rickford (eds.). 1998. African-American English: Structure, History and Use (1 edition). London, New York: Routledge. 
Barnes, Tiffany D., and Stephanie M. Burchard. 2013. "Engendering' Politics, The Impact of Descriptive Representation on Women's Political Engagement in Sub-Saharan Africa." Comparative Political Studies 46 (7): 767-90. https://doi.org/10.1177/0010414012463884

Bianchi, Claudia. 2014. "Slurs and Appropriation: An Echoic Account." Journal of Pragmatics 66: 35-44. https://doi.org/10.1016/j.pragma.2014.02.009

Brontsema, Robin. 2004. "A Queer Revolution: Reconceptualizing the Debate over Linguistic Reclamation." Colorado Research in Linguistics 17: 1-17. https://doi.org/10.25810/dky3-zq57

Burnett, Heather. 2020. "A Persona-Based Semantics for Slurs." Grazer Philosophische Studien 97 (1): 39-62. https://doi.org/10.1163/18756735-09701004

Camp, Elisabeth. 2013. "Slurring Perspectives." Analytic Philosophy 54 (3): 33049. https://doi.org/10.1111/phib.12022

Camp, Elisabeth. 2018. "A Dual Act Analysis of Slurs." In Bad Words: Philosophical Perspectives on Slurs, edited by David Sosa, 29-59. Oxford, Oxford University Press. 10.1093/oso/9780198758655.001.0001

Childs, Sarah, and Mona Lena Krook. 2009. "Analysing Women's Substantive Representation: From Critical Mass to Critical Actors." Government and Opposition 44 (2): 125-45. https://doi.org/10.1111/j.1477-7053.2009.01279.x

Croom, Adam. 2011. "Slurs". Language Sciences 33 (3): 343-58. https://doi.org/10.1016/j.langsci.2010.11.005

Croom, Adam. 2013. "How to Do Things with Slurs: Studies in the Way of Derogatory Words". Language $\&$ Communication 33 (s): 177-204. https://doi.org/10.1016/j.langcom.2013.03.008

Croom, Adam. 2014. "Spanish Slurs and Stereotypes for Mexican-Americans in the USA: A Context-Sensitive Account of Derogation and Appropriation". Sociocultural Pragmatics 2 (2): 145-79. https://doi.org/10.1515/soprag-2014-0007

Dahlerup, Drude, and Lenita Freidenvall. 2010. "Judging Gender Quotas: Predictions and Results." Policy $\&$ Politics 38 (3): 407-25.

10.1332/030557310X521080

Darwall, Stephen L. 1977. "Two Kinds of Respect." Ethics 88 (1): 36-49. https://doi.org/10.1086/292054

Dworkin, Gerald. 2017. "Paternalism." In The Stanford Encyclopedia of Philosophy (Spring 2017 Edition), edited by Edward N. Zalta. URL = https://plato.stanford.edu/archives/spr2017/entries/paternalism/

Franceschet, Susan, and Jennifer M. Piscopo. 2008. "Gender Quotas and Women's Substantive Representation: Lessons from Argentina." Politics $\&$ Gender 4 (3): 393-425. https://doi.org/10.1017/S1743923X08000342 
Fullinwider, Robert. 2017. "Affirmative Action." In The Stanford Encyclopedia of Philosophy (Summer 2017 Edition), edited by Edward N. Zalta. URL = https://plato.stanford.edu/archives/sum2017/entries/affirmative-action/

Galinsky, Adam D., Kurt Hugenberg, Carla Groom, and Galen V. Bodenhausen. 2003. "The Reappropriation of Stigmatizing Labels: Implications for Social Identity." In Identity Issues in Groups, edited by Jeffrey T. Polzer, 221-56. Emerald Group Publishing Limited. https://doi.org/10.1016/S15340856(02)05009-0

Galinsky, Adam D., Cynthia S. Wang, Jennifer A. Whitson, Eric M. Anicich, Kurt Hugenberg, and Galen V. Bodenhausen. 2013. "The Reappropriation of Stigmatizing Labels: The Reciprocal Relationship between Power and Self-labeling." Psychological Science 24 (10): 2020-9. https://doi.org/10.1177/0956797613482943

Herbert, Cassie. 2015. "Precarious Projects: the Performative Structure of Reclamation." Language Sciences 52: 131-138. https://doi.org/10.1016/j.langsci.2015.05.002

Hess, Leopold. forthcoming. "Slurs: Semantics and Pragmatics Theories of Meanings." In The Cambridge Handbook of Philosophy of Language, edited by Piotr Stalmaszczyk. Cambridge University Press.

Jeshion, Robin. 2013a. "Expressivism and the Offensiveness of Slurs." Philosophical Perspectives 27 (1): 231-59. https://doi.org/10.1111/phpe.12027

Jeshion, Robin. 2013b. "Slurs and Stereotypes." Analytic Philosophy 54 (3): 31429. https://doi.org/10.1111/phib.12021

Jeshion, Robin. 2020. "Pride and Prejudiced: On the Appropriation of Slurs." Grazer Philosophische Studien 97 (1): 106-37.

https://doi.org/10.1163/18756735-09701007

Kennedy, Randall. 2002. Nigger: The Strange Career of a Troublesome Word. New York: Vintage.

Kittilson, Miki Caul, and Leslie A. Schwindt-Bayer. 2012. The Gendered Effects of Electoral Institutions: Political Engagement and Participation. New York: Oxford University Press. 10.1093/acprof:oso/9780199608607.001.0001

Kleinman, Sherryl, Matthew B. Ezzell, and Corey Frost. 2009. "Reclaiming Critical Analysis: The Social Harms of 'Bitch'." Sociological Analysis 3 (1): 46-68.

Marques, Teresa. 2017. "Pejorative Discourse Is Not Fictional." Thought: A Journal of Philosophy 6 (4): 250-60. https://doi.org/10.1002/tht3.258

Marques, Teresa, and Manuel García-Carpintero. 2020. "Really Expressive Presuppositions and How to Block Them." Grazer Philosophische Studien 97 (1): 13858. https://doi.org/10.1163/18756735-09701008 
Matland, Richard E. 2006. "Electoral Quotas: Frequency and Effectiveness." In Women, Quotas and Politics, edited by Drude Dahlerup, 275-92. London, Routledge. 10.1080/00344890701363227

Miščević, Nenad, and Julija Perhat. 2016. A Word Which Bears a Sword: Inquiries into Pejoratives. Zagreb, KruZak.

Murray, Rainbow. 2010. "Second among Unequals? A Study of Whether France's 'Quota Women' Are Up to the Job." Politics $\&$ Gender 6 (1): 93-118. https://doi.org/10.1017/S1743923X09990523

Nunberg, Geoffrey. 2018. "The Social Life of Slurs." In New Work on Speech Acts, edited by Daniel Fogal, Daniel W. Harris, and Matt Moss, 237-95. Oxford: Oxford University Press. 10.1093/oso/9780198738831.001.0001

O'Brien, Diana Z., and Johanna Rickne. 2016. "Gender Quotas and Women's Political Leadership." American Political Science Review 110 (1): 112-26. https://doi.org/10.1017/S0003055415000611

Popa-Wyatt, Mihaela. 2020. "Reclamation: Taking Back Control of Words". Grazer Philosophische Studien 97 (1): 159-76. https://doi.org/10.1163/18756735-09701009

Richard, Mark. 2008. When Truth Gives Out. Oxford: Oxford University Press. Ritchie, Katherine. 2017. "Social Identity, Indexicality, and the Appropriation of Slurs." Croatian Journal of Philosophy 17 (2): 155-80. hrcak.srce.hr/195051

Schwindt-Bayer, Leslie A. 2009. "Making Quotas Work: The Effect of Gender Quota Laws on the Election of Women." Legislative Studies Quarterly 34 (1): 5-28. https://www.jstor.org/stable/20680225

Stanley, Jason. 2015. How Propaganda Works. Princeton: Princeton University Press.

Tirrell, Lynne. 1999. "Derogatory Terms: Racism, Sexism, and the Inferential Role Theory of Meaning". In Language and Liberation: Feminism, Philosophy, and Language, edited by Christina Hendricks, and Kelly Oliver, 41-77. Albany (NY): SUNY Press.

Thompson, Nicole Akoukou. 2013. "John Leguizamo \& Kanye West use Re-appropriation to Change Perceptions." Latin Post, 11 November. http://www.latinpost.com/articles/3547/20131111/

Zeman, Dan. 2021. "A Rich-Lexicon Theory of Slurs and Their Uses." Inquiry, https://doi.org/10.1080/0020174X.2021.1903552

Organon F 28 (3) 2021: 672-688 